\title{
Oesophageal motility in the irritable bowel syndrome
}

\author{
P J WHORWELL, CAROLE CLOUTER, COLIN L SMITH
}

\begin{abstract}
Oesophageal motility was assessed in 30 patients with the irritable bowel syndrome and controls matched for age and sex. Lower oesophageal sphincter pressure was significantly lower in the patients than their controls (mean pressures 13.8 and $23.8 \mathrm{~cm} \mathrm{H}_{2} \mathrm{O}$ respectively), and the same degree of difference between patients and controls was maintained in all age groups. In addition, spontaneous activity, repetitive contractions, and the presence of variable-amplitude and simultaneous waves were significantly more common in the patients, who were also more likely to have more than one abnormal pattern of motility. There was no difference in upper oesophageal sphincter pressure between the two groups.

These findings may help to explain why patients with the irritable bowel syndrome may complain of upper gastrointestinal symptoms, including heartburn and dysphagia. The results suggest that the syndrome may be a more widespread disorder of smooth muscle, or its innervation, than was previously thought.
\end{abstract}

\section{Introduction}

The irritable bowel syndrome defines a symptom complex usually consisting of a combination of diarrhoea, constipation, abdominal pain, and other large-bowel symptoms. ${ }^{1} \mathrm{~A}$ barium enema may show hypersegmentation, and motility studies of the colon often show abnormalities. ${ }^{2-5}$ A recent study showed that small-intestinal pressure was also disturbed, suggesting that the disorder may not be confined to the colon. ${ }^{6}$ In addition, patients with the syndrome often complain of upper gastrointestinal symptoms. Since the irritable bowel syndrome may therefore be a more diffuse disorder than was previously supposed and oesophageal motility has not been assessed in this condition, we

\footnotetext{
Professorial Medical Unit, Southampton General Hospital, Southampton SO9 4XY

P J WHORWELL, MD, MRCP, lecturer in medicine

CAROLE CLOUTER, medical student

COLIN L SMITH, MD, FRCP, senior lecturer in medicine
}

performed oesophageal manometry in patients with the syndrome and matched controls.

\section{Patients and methods}

We studied 30 patients with the irritable bowel syndrome (17 women, 13 men; mean age 39 years) and 30 age- and sex-matched healthy controls selected from hospital staff. Patients were considered to have the irritable bowel syndrome if they had abdominal pain with or without diarrhoea or constipation. Relief of pain by defecation, abdominal distension, a feeling of incomplete evacuation, and a response to a high-residue diet were taken as useful additional symptoms. The blood picture, erythrocyte sedimentation rate, and results of sigmoidoscopy, rectal biopsy, and barium enema were normal in all patients. The symptoms of the patients, including dysphagia and heartburn, were recorded on data sheets for correlation with manometric findings.

Oesophageal manometry was performed on fasting subjects, the patients' medication having been stopped 48 hours previously. Measurements were made using a $125 \mathrm{~cm}$ long, triple $(1.1 \mathrm{~mm})$ lumen tube with distal openings separated $5 \mathrm{~cm}$ vertically and spaced radially at $120^{\circ}$. Each lumen was perfused with distilled water at $1.36 \mathrm{ml} / \mathrm{min}$ using a capillary infusion system ${ }^{7}$ (Arndorfer Medical Specialties) with Elcomatic pressure transducers connected to a Devices Multichannel pen recorder. The lower oesophageal sphincter pressure was measured using both the station ${ }^{8}$ and the rapid pull-through techniques. ${ }^{9}$ End expiratory pressures, with the gastric baseline as zero reference, were used for measurements obtained by the station method.

In the lower portion of the body of the oesophagus the tube was left in the same position for five minutes. The number of spontaneous waves not induced by swallowing was recorded and expressed as number per minute. One or more waves per minute were regarded as spontaneous activity. For the rest of the examination the tube was withdrawn at $2 \mathrm{~cm}$ intervals with wet $(5 \mathrm{ml}$ water) and dry swallows at each level. The presence of simultaneous and incompletely propagated waves was recorded. Variable-amplitude waves (fluctuating outside a normal range of $40-110 \mathrm{~cm} \mathrm{H}_{2} \mathrm{O}$ ) and repetitive waves (a contractile response with more than one peak of pressure after a single swallow) were also noted. The upper oesophageal sphincter pressure was recorded by the station method. All tracings were analysed blind after they had been coded.

\section{Results}

The figure shows the lower oesophageal sphincter pressures in the patients and controls as determined by the station method. The sphincter pressure was significantly lower in the patients than the 
controls ( $p<0.001$, paired $t$ test). Table I shows the mean sphincter pressure as determined by the station method in different age groups; the same degree of difference between patients and controls was maintained in all age groups. A close correlation was found between results obtained by the station and rapid pull-through techniques $(\mathrm{r}=0.71, \mathrm{p}<0.001)$.

Table II shows the incidence of various patterns of activity recorded in the oesophageal body. The patients had significantly more spontaneous activity, repetitive contractions, and variable-amplitude and simultaneous waves. In addition, they were more likely to have more than one abnormal pattern of motility. No particular manometric abnormality correlated with any pattern of symptoms of the irritable bowel syndrome. There was no difference in the upper oesophageal sphincter pressures between the two groups.

\begin{tabular}{|c|c|c|}
\hline$\underset{\text { (years) }}{\text { Age }}$ & Controls & Patients \\
\hline $\begin{array}{c}20-35(\mathrm{n}=14) \\
36-50(\mathrm{n}=9) \\
50(\mathrm{n}=7)\end{array}$ & $\begin{array}{c}25 \cdot 2+1 \cdot 8 \\
25 \cdot 2+1 \cdot 8 \\
19 \cdot 26=1.59\end{array}$ & $\begin{array}{r}16.95: 2.4 \\
13 \cdot 4: 2 \cdot 1 \\
12 \cdot 4: 3 \cdot 3\end{array}$ \\
\hline
\end{tabular}

significantly from those in the controls. These findings suggest that the irritable bowel syndrome may be a more diffuse disorder than was originally thought.

Oesophageal symptoms are increased in patients with the irritable bowel syndrome, ${ }^{10}$ and possibly our results help to explain this observation. Interestingly, all of our patients who complained of dysphagia had some degree of abnormal oesophageal motility. Lower oesophageal sphincter pressure is inclined to decrease with age, and this was confirmed when the subjects were grouped according to age (table I). Nevertheless, the same significant differences between patients and controls were maintained irrespective of age group.

The abnormal findings in this study were confined to the smooth-muscle portion of the oesophagus, no abnormalities being found in the striated upper oesophageal sphincter. Abnormal colonic ${ }^{2-5}$ and, more recently, small-intestinal ${ }^{6}$ motility has been shown in patients with the irritable bowel syndrome. The colonic hypermotility may be exacerbated by food or cholinergic stimulation, and gut hormones may possibly play a part. Cholecystokinin increases intestinal motor activity and reproduces symptoms ${ }^{11} 12$ in some patients with the irritable bowel syndrome, and in the light of our findings it is noteworthy that cholecystokinin decreases the lower oesophageal sphincter pressure. ${ }^{13}$

TABLE II-Comparison of incidence of manometric findings in body of oesophagus in patients with irritable bowel syndrome and matched controls. Figures are numbers (\%) of subjects

\begin{tabular}{|c|c|c|c|c|c|}
\hline & $\begin{array}{c}\text { Spontaneous } \\
\text { activity }\end{array}$ & $\begin{array}{l}\text { Variable- } \\
\text { amplitude } \\
\text { waves }\end{array}$ & $\begin{array}{l}\text { Simultaneous } \\
\text { waves }\end{array}$ & $\begin{array}{c}\text { Repetitive } \\
\text { contractions }\end{array}$ & $\begin{array}{l}\text { Incomplete } \\
\text { waves }\end{array}$ \\
\hline $\begin{array}{l}\text { Patients }(n=30) \\
\text { Controls }(n=30) \\
\text { Significance* }\end{array}$ & $\begin{array}{c}16(53.3) \\
8(26 \cdot 7) \\
p=0.05\end{array}$ & $\begin{array}{r}13(43.3) \\
4(13.3) \\
\mathrm{p}=0.02\end{array}$ & $\begin{array}{r}15(50.0) \\
4(13.3) \\
p=0.01\end{array}$ & $\begin{array}{c}13(43.3) \\
5(16.7) \\
p=0.05\end{array}$ & $\begin{array}{l}9(30 \cdot 0) \\
7(23 \cdot 3) \\
\text { NS }\end{array}$ \\
\hline
\end{tabular}

*Significance determined by $\chi^{2}$ test.

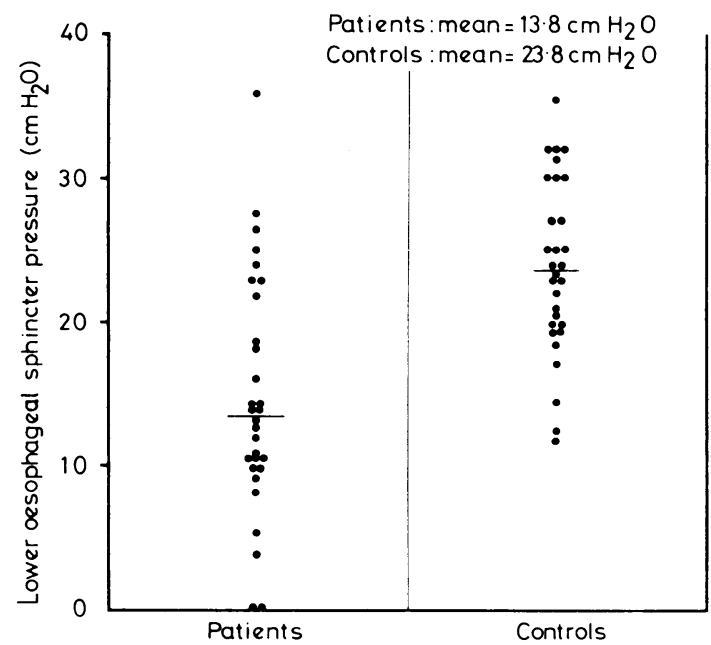

Lower oesophageal sphincter pressures in patients with irritable bowel syndrome and matched controls.

Eight patients with the irritable bowel syndrome complained of dysphagia but upper endoscopic examination showed no abnormality; all of these subjects had some degree of manometric abnormality.

\section{Discussion}

This study clearly shows that, compared with matched controls, patients with the irritable bowel syndrome have a significantly reduced lower oesophageal sphincter pressure. Motility patterns within the oesophageal body also differed
Our results suggest that the irritable bowel syndrome may be a more widespread disorder of smooth muscle, or its innervation, than has been previously recognised.

\section{References}

${ }^{1}$ Manning AP, Thompson WG, Heaton KW, Morris AF. Towards positive diagnosis of the irritable bowel. $\mathrm{Br}$ Med F 1978;ii:653-4.

2 Chaudhary NA, Truelove SC. The irritable bowel syndrome. $Q \mathcal{F ~ M e d}$ $1962 ; 31: 307$.

${ }^{3}$ Connell AM. Motility of the pelvic colon. Abdominal pain associated with colonic hypermotility. Gut 1965;6:105-12.

${ }^{4}$ Connell AM. The motility of the pelvic colon. II. Paradoxical motility in diarrhoea and constipation. Gut $1962 ; 3: 342$.

5 Wangel AG, Deller DJ. Intestinal motility in man. III. Mechanisms of constipation and diarrhea with particular reference to the irritable colon syndrome. Gastroenterology 1965;48:69.

6 Thompson DG. Abnormal small bowel motility demonstrated by radiotelemetry in a patient with irritable colon. Lancet $1979 ; \mathrm{i}: 22-9$.

${ }^{7}$ Arndorfer RC, Stef JJ, Dodds WJ, Lineham JH, Hogan WJ. Improved infusion system for intraluminal esophageal manometry. Gastroenterology $1977 ; 73: 23-7$

${ }^{8}$ Hay DJ, Goodall RJR, Temple JG. The reproducibility of the station pull-through technique for measuring lower oesophageal sphincter pressure. Br f Surg 1979;66:93-7.

${ }^{9}$ Dodds WJ, Hogan WJ, Stef JJ, Miller WN, Lyndon SB, Arndorfer RC. A rapid pull-through technique for measuring lower esophageal sphincter pressure. Gastroenterology 1975;68:437-43.

10 Watson WC, Sullivan SN, Corke M, Rush D. Incidence of oesophageal symptoms in patients with irritable bowel syndrome. Gut 1976;17:827.

${ }^{11}$ Harvey RF, Read AE. Effects of CCK on colonic motility and symptoms in patients with irritable bowel syndrome. Gut 1972;13:837-8.

12 Harvey RF, Read AE. Effects of CCK on colonic motility and symptoms in patients with irritable bowel syndrome. Lancet 1973;i:1-3.

${ }^{13}$ Snape WJ, Cohen S. Hormonal control of esophageal function. Arch Intern Med 1976;136:538-42.

(Accepted 22 fanuary 1981) 